\title{
LEWIS CARROLL
}

A Handbook of the Literature of the Rev. C. L. Dodgson (Lewis Carroll). By Sidney Herbert Williams and Falconer Madan. Oxford University Press, 1931. xxv +336 pp. and 16 plates.

Catalogue of an Exhibition at Columbia University to Commemorate the one hundredth Anniversary of the Birth of Lewis Carroll (Charles Lutwidge Dodgson) 1832-1898. New York, Columbia University Press, 1932. $\mathrm{x}+153$ pp. and 3 plates.

The Lewis Carroll Centenary in London, 1932. Including a Catalogue of the Exhibition with Notes; an Essay on Dodgson's Illustrators by Harold Hartley; and additional literary pieces (chiefly unpublished). Edited by Falconer Madan. With six illustrations. London, J. and E. Bumpus, 1932. xx+149 pp. and 6 plates. The paper covered edition is without the plates and the "additional literary pieces."

Charles Lutwidge Dodgson (January 27, 1832-January 14, 1898), the centenary of whose birth has recently been so generally observed in the English speaking world,* received a B.A. from Oxford University in 1854, was a mathematical lecturer there $1855-81$, and was ordained deacon in 1861 . Some of his more substantial mathematical publications were the following:

* Until recently the chief sources of information concerning Mr. Dodgson were: E. V. Lucas, Dictionary of National Biography, Supplement, London, vol. 2 (1901), pp. 142-144. S. D. Collingwood, The Life and Letters of Lewis Carroll, London, 1899 , xx +448 pp.; bibliography, pp. 441-443. S. D. Collingwood, The Lewis Carroll Picture Book, London, 1899. The most charming of all sketches is that of W. De La Mare, Lewis Carroll, London, 1932, 62 pp. (Reprinted from pp. 218-255 of The Eighteen-Eighties. Essays by Fellows of the Royal Society of Literature, Cambridge, England, 1930. Abridged in Fortnightly Review, vol. 134, Sept., 1930, pp. 319-331, and in Saturday Review of Literature, New York, vol. 7 (Oct. 11, 1930), pp. 202-203.) Other recent publications are: (a) L. Reed, Life of Lewis Carroll, London, 1932, 142 pp. (b) R. B. Braithwaite, Lewis Carroll as a logician, Mathematical Gazette, vol. 16, July, 1932, pp. 174-178. (c) T. Maynard, Lewis Carroll, mathematician and magician, Catholic World, vol. 135, May, 1932, pp. 193-201. (d) E. Wilson, The poet logician, New Republic, vol. 71 (May 18, 1932), pp. 19-21. (e) C. Hargreaves, Alice's recollections of Carrollian days as told by her son, Cornhill Magazine, vol. 73 (July, 1932), pp. 1-12. (f) E. M. Arnole, Reminiscences of Lewis Carroll, Atlantic Monthly, vol. 143 (June, 1929), pp. 782-789. (g) W. R. Benét, Round about Parnassus, Saturday Review of Literature, vol. 6 (Oct. 26, 1929), p. 316. (h) D. E. Smith and V. Sanford, Mathematics Teacher, vol. 15 (Jan., 1932), pp. 38-43. (i) New York Times Magazine, Jan. 24, 1932, (1) G. K. Chesterton, The 100th birthday of nonsense; (2) C. Price, Alice lives in wonderland-and in fact; (3) P. W. Wilson, Dodgson-Carroll: a dual character. 
1. Syllabus of Plane Algebraical Geometry (1860), 2. Elementary Treatise on Determinants (1867), 3. Euclid and his Modern Rivals (1879; second ed., 1885) and Supplement (1885), 4. Curiosa Mathematica (2 v., 1888-93, 4 eds.), and 5. Symbolic Logic, Part I. Elementary (1896, 4 eds.). Number 3 is mainly thrown into dramatic form and is a critique of modern substitutes for Euclid's Elements, which were doubtless inspired, in part, by the Association for the Improvement of Geometrical Teaching and its various Reports (1871-93) and Syllabi (1875-89). Part I of number 4 dealt with "A new Theory of Parallels," and Part II was entitled "Pillow-Problems thought out during sleepless nights." The latter was a set of seventy-two problems chiefly in algebra, plane geometry, and trigonometry. Number 5 is the only one of the above works published under the pseudonym "Lewis Carroll," first used by him in 1856.

But Lewis Carroll is chiefly known throughout the world as the author of Alice's Adventures in Wonderland, first published in 1865 (with the remarkable illustrations of Sir John Tenniel), and of Through the Looking Glass and What Alice Found There (1871). Of the former there have been scores of editions and it has been translated into Braille, Chinese, Czech, Dutch, Esperanto, French, German, Hebrew, Hungarian, Irish, Italian, Japanese, Norwegian, Russian, shorthand, Spanish, and Swedish. Lewis Carroll's original for his "Alice" was Alice Liddell, daughter of the Dean of Christ Church, Oxford. She became Mrs. Hargreaves and is still living. About a year ago she visited New York, at the time of the Lewis Carroll exhibition at Columbia University, which conferred on her an honorary degree. The first draft, unfinished and unpolished, of Alice's Adventures in Wonderland was Alice's Adventures Under Ground, which was reproduced in facsimile, and published, in 1886. In April 1928, the manuscript was sold for $£ 15,400$ to Dr. Rosenbach of Philadelphia. In the following October he sold it for $£ 30,000$ to Mr. Edridge R. Johnson of Morristown, N.J.

The first separate bibliography of the writings of Lewis Carroll was the volume by S. H. Williams published in London in 1924 (xiv +142 pp.). The material here given is, however, but a small fraction of that given in the Handbook, by Williams and F. Madan, issued by the Oxford University Press. This is a most admirable volume packed with all sorts of bibliographic, biographic, and other information of interest to the general reader or specialist. Collections of Carrolliana are here also described. The authors state that "there are only two first-class collections, the public one at Harvard University, $\cdots$, and the one owned by Mr. M. L. Parrish of Philadelphia." In connection with this latter collection it is stated: "In the collection are about 500 of Dodgson's Mathematical Papers, without recourse to which the extent and thoroughness of his work in this line cannot be appreciated; and parts are in a condition ready for publication."

The Catalogue of the exhibition at Columbia University contains 415 items most of which were loaned by collectors, Mr. Johnson, Mr. Parrish, Professor Zanetti of Columbia University, The Pierpont Morgan Library, Mr. Owen D. Young, and many others. The catalogue contains also four portraits and an index. The paper cover copies cost 35 cents each; but the red cloth numbered copies cost $\$ 5.00$ apiece! 
The Catalogue of the exhibition in London is much more attractive in every way. The notes for the 691 entries are more profuse and the additional material is of special interest. There were quite a number of items neither manuscript nor printed.

The verse of Dodgson has been collected in a single volume with an introduction by J. F. McDermott (New York, 1929). Much of this verse has been set to music,* some of which is to be found on phonographic records. The number of mathematicians who have written verse, or dramas, is quite large. But the number of those who have produced a great effect on their country's literature, like Lewis Carroll in the writing of nonsense, is exceedingly small.

\section{R. C. Archibald}

\section{PICARD ON CURVES AND SURFACES}

\section{Quelques Applications Analytiques de la Theorie des Courbes et des Surfaces} Algébriques. By M. Emile Picard. Paris, Gauthier-Villars, 1931. viii $+224 \mathrm{pp}$.

This volume is published as Fascicule 9 of the Cahiers scientifiques. It contains the course given at the Sorbonne in 1930. The first chapters discuss Abelian integrals and the problem of inversion for $p=1$ and $p>1$. After mentioning the theorem of Jacobi that a single-valued function in one variable can have no more than two distinct periods, the corresponding theorem for two variables is proved. Its statement is that a single-valued function of two variables can have no more than four pairs of distinct periods. Furthermore, it is proved that if one imposes upon a quadruply periodic function the condition of being rational at any finite point, there necessarily exists a relationship bebetween the four pairs of periods. A set of equations expressing this relationship is found.

Chapter 3 mentions the known theorems (a) that the coordinates of a point of an algebraic curve of genus zero are expressible as rational functions of a single parameter, (b) that the coordinates of a point of a curve of genus one are expressible by doubly periodic functions which are meromorphic at any finite point. In these two cases, the functions which give the parametric representation have only isolated poles or singular points throughout the whole plane. Then follows the more general theorem due to Poincaré, (c) that the coordi nates of any point of an algebraic curve can be expressed by single-valued functions of a single parameter, but when the genus is greater than one, the essential singularities of these functions are no longer isolated.

The solution of the differential equation

$$
F\left(u, \frac{d u}{d z}\right)=0,
$$

which possesses a meromorphic integral at any finite point of the plane, requires nothing but exponential functions and doubly periodic functions. The solution of

* The work of Williams and Madan lists (pp. 263-281) nearly 70 "dramatizations and musical settings" of Carroll's Alice and verse. 